\title{
PENTINGNYA TES KEMAHIRAN BERBAHASA INDONESIA BAGI PEMELAJAR BIPA BERTUJUAN AKADEMIK
}

\author{
Ari Kusmiatun \\ Universitas Negeri Yogyakarta \\ email: arik@uny.ac.id
}

\begin{abstract}
Abstrak
Penelitian ini bertujuan untuk mendeskripsikan kebutuhan pemelajar asing dalam program BIPA akademik terhadap tes kemahiran berbahasa Indonesia akademik. Penelitian ini merupakan tahap awal dari penelitian pegembangan tes kemahiran berbahasa Indonesia yang diperuntukkan bagi pemelajar BIPA bertujuan akademik. Jenis penelitian dalam tahap awal atau studi pendahuluan ini adalah penelitian kualitatif. Penelitian ini mendeskripsikan beberapa hal terkait kebutuhan tes kemahiran bagi pemelajar asing bertujuan akademik. Pengumpulan data dilakukan dengan menggunakan teknik observasi, dokumentasi, angket, dan wawancara. Subjek penelitiannya adalah pemelajar asing, dosen pengajar yang di kelasnya terdapat mahasiswa asing, dan pengelola program BIPA bertujuan akademik. Teknik analisis data yang digunakan adalah kualitatif. Keabsahan data dalam penelitian ini menggunakan trianggulasi data, berupa tianggulasi sumber dan metode. Hasil penelitian menunjukkan bahwa kebutuhan tes kemahiran berbahasa Indonesia diperlukan oleh para pemelajar asing yang bertujuan akademik. Dengan tes ini, kemampuan berbahasa Indonesia mereka dapat terdeteksi dan disikapi sehingga mereka dapat menjalani perkuliahan dengan baik dan lancar.
\end{abstract}

Kata Kunci: tes kemahiran berbahasa Indonesia, pemelajar asing, bertujuan akademik

\section{PENDAHULUAN}

Kemampuan berbahasa Indonesia seseorang dapat diketahui dengan adanya perangkat tes kemampuan berbahasa Indonesia. Selama ini, secara terstandar tes Uji Kemahiran Bahasa Indonesia (UKBI) telah dikembangkan oleh badan bahasa. Tes UKBI diberlakukan untuk penutur asing ataupun penutur jati bahasa Indonesia. Namun demikian, tes UKBI masih bersifat umum dan kurang cocok diterapkan untuk para pemelajar asing yang bertujuan akademik. Bahkan, tes UKBI juga masih menuai kontroversi sebagai alat tes bagi penutur asing.

Saat ini, hampir setiap instansi BIPA memiliki sistem tersendiri dalam menguji kemahiran berbahasa Indonesia pemelajar asing, baik itu melalui UKBI maupun tes lainnya. Pada dasarnya, tes-tes tersebut memiliki tujuan yang sama, yakni untuk mengetahui level berbahasa Indonesia pemelajar asing. Hanya saja, mereka menggunakan istilah yang berbeda. Akan tetapi, tes UKBI atau tes lainnya tersebut masih bersifat general sehingga tidak sesuai jika diberikan kepada pemelajar asing bertujuan akademik.

Pemelajar asing yang sudah mengikuti program BIPA atau dapat berbahasa Indonesia perlu diuji kompetensinya dengan piranti tes yang berbeda dengan penutur asli. Jika evaluasi bagi penutur asli bahasa Indonesia dilakukan dengan Uji Kemahiran Berbahasa Indonesia (UKBI), maka untuk menguji penutur asing diperlukan piranti tes tersendiri, yakni Tes Kemahiran Berbahasa Indonesai bagi Penutur Asing (TKBIPA). TKBIPA dapat ditempuh bagi penutur asing yang ingin mengetahui sampai sejauh mana penguasaannya terhadap bahasa bahasa Indonesia. UKBI perlu dikembangkan berdasarkan analisis kebutuhan pemelajar asing sehingga tes tersebut dapat diberikan kepada pemelajar asing. Oleh karena itu, makalah ini akan membahas tentang analisis kebutuhan mahasiswa asing terhadap Tes Kemahiran Berbahasa Indonesia Bertujuan Akademik. Dengan dilakukan analisis kebutuhan mahasiswa asing tersebut, diharapkan dapat mengembangkan model Tes Kemahiran Berbahasa Indonesia 
Bertujuan Akademik dalam bentuk proficiency test.

Evaluasi ada dalam berbagai bentuk dan memiliki muatan tujuan yang spesifik. Salah satunya adalah tes kemahiran berbahasa. Secara luas, evaluasi diartikan sebagai proses merencanakan, memperoleh, dan menyediakan informasi atau data yang diperlukan sebagai dasar pengambilan keputusan (Kusmiatun, 2015). Evaluasi adalah sebuah kegiatan yang disengaja dan direncana, baik internal maupun eksternal pembelajaran.

Tes kemahiran berbahasa Indonesia merupakan tes eksternal yang tidak terikat oleh pembelajaran. Tes ini bukan merupakan tes pencapaian belajar, tetapi lebih pada tes kemampuan berbahasa (proficiency test). Tes semacam ini mempunyai tingkatan kesulitan yang disesuaikan berdasar kompetensi berbahasa yang dikuasai subjeknya (Djiwandono, 2008). Tes ini juga diselaraskan untuk penutur asing yang pastinya berbeda dengan penutur jati. Heaton (1988:64) menyatakan bahwa pada umumnya, otak manusia memiliki keterbatasan kapasitas dalam meresepsi informasi san tidak banyak bentuk yang dibangun dalam bahasa. Hal ini terjadi secara khusus pada pembelajaran bahasa asing. BIPA menempatkan bahasa Indonesia sebagai bahasa asing, sehingga hal ini berlaku dalam pembelajaran BIPA.

Suyitno (2005) membagi evaluasi dalam pembelajaran BIPA dalam beberapa jenis. Evaluasi dibedakan atas waktu pelaksanaannya, tujuannya, materinya, bentuknya, dan cara evaluasi tersebut dilakukan. Selain itu, cakupan kemahiran berbahasa meliputi keempat keterampilan berbahasa yang di dalamnya mengandung unsur pengetahuan bahasa (kosakata dan tata bahasa). Tes kemahiran berbahasa, mencakup empat keterampilan berbahasa yang masing-masing berbeda sesuai aspek penguasaannya. Tes menyimak dilakukan dengan berbagai macam cara dan lebih mengarah pada ranah kognitif untuk mengetahui pemahaman pebelajar atas tuturan lisan bahasa Indonesia. Tes ini membutuhkan media audio dan atau audiovisual. Tes berbicara mengukur kemampuan berbahasa lisan. Keterampilan berbicara merupakan suatu kompleks karena melibatkan banyak unsur, bahasa dan nonbahasa. Tes berbi- cara dilakukan secara individual. Harris (1969) menyatakan bahawa tes berbicara adalah tes yang paling sulit. Ada setidaknya lima aspek yang harus diperhatikan dalam tes ini, yaitu: (a) ucapan, (b) kosakata/diksi, (c) tata bahasa, (d) kefasihan, dan (e) pemahaman. Keterampilan berbahasa lainnya adalah membaca dan menulis. Membaca mempunyai arah mengukur kemampuan pemahaman pebelajar pada bacaan, sedangkan menulis mengarah pada kemampuan menyampaikan informasi/pendapat/ perasaan dalam wujud tertulis. Keterampilan membaca dilakukan untuk: (a) memahami informasi, (b) menerima, mengklarifikasi, menganalisis, dan menyimpulkan informasi, (c) ketepatan lafal dan intonasi ketika membaca dalam bahasa Indonesia. Jenis bacaan akan menentukan hasil tes. Pembuat alat tes harus dapat memilih bacaan yang tepat sebagai bahan tes membaca. Hughes (1989:119-120) menyebutkan bahwa pemilihan bacaan harus mempertimbangkan beberapa hal. Sementara untuk menulis, evaluasinya dengan cara menulis.

BIPA merupakan salah satu bentuk pembelajaran bahasa Indonesia yang subjek pelajarnya adalah orang asing, bukan penutur asli bahasa Indonesia. Bahasa Indonesia dalam BIPA dapat menjadi bahasa kedua atau bahasa bahasa asing bagi pemelajarnya. Pembelajaran BIPA menjadikan orang (penutur) asing dapat menguasai bahasa Indonesia dan mampu berbahasa Indonesia untuk berbagai keperluan.

Pembelajaran BIPA mempunyai karakter berbeda dengan pembelajaran bahasa Indonesia pada umumnya. Salah satunya adalah karena pemelajarnya adalah orang dewasa. Pembelajaran bahasa untuk dewasa memiliki karateristik khusus yang berbeda (Illeris, 2011; Rogers, 1999; Ellis, 1995; Robinson (Ed.), 2002; Lightbown \& Spada, 2013; Leaver, Erhamn, and Schehman 2005:19; Fry, Ketteridge, and Marshall, 2013). Ellis (1995:198) juga mengungkapkan bahwa pelajar bahasa kedua mempunyai sikap yang berbeda terhadap bahasa kedua (bahasa yang dipelajari), penutur bahasa kedua, kultur/budaya bahasa kedua, nilai sosial dalam mempelajari bahasa kedua, pemakaian bahasa kedua, dan dirinya sendiri sebagai anggota budayanya sendiri. 
Pembelajaran BIPA mengacu pada aspek fungsional bahasa. Pelajar asing belajar bahasa Indonesia dengan berbagai keperluan atau tujuan. Secara umum, pembelajaran BIPA berorientasi pada kebutuhan komunikasi. Pembelajaran ditujukan untuk membekali pemelajar agar dapat berkomunikasi menggunakan bahasa Indonesia dengan baik. Namun, salah satu bentuk pemelajaran BIPA lainnya adalah BIPA yang ditujukan untuk keperluan akademik. Artinya, pemelajar mempunyai tujuan akademik seperti studi lanjut di Indonesia, meneliti, maupun bidang pengajaran atau akademik lainnya. BIPA yang demikian ini dinamakan BIPA bertujuan akademik. Kusmiatun (2017) menyebutkan bahwa dalam BIPA jenis ini pembeda dengan BIPA lainnya adalah pada konten materinya yang mengarah pada bidang akademik. Dengan demikian, uji kemahiran untuk BIPA jenis ini juga harus disesuaikan dengan substansi BIPA yang bersangkutan. BIPA akademik selaras dengan English for Academic Purposes yang dalam kontennya Hayland (2006) menyebutkan bahwa secara general AEP mengarah pada kebutuhan pelajar terhadap keterampilan berbahasa yang akan digunakan untuk: (1) mendengarkan dosen mengajar di kelas; (2) berpatisipasi dalam supervisi, seminar, tutorial; (3) membaca buku, artikel, dan materi lainnya; dan (4) menulis esai, jawaban ujian, laporan, dan tesis.

\section{METODE}

Jenis penelitian dalam tahap awal atau studi pendahuluan ini adalah penelitian kualitatif. Penelitian ini mendeskripsikan beberapa hal terkait kebutuhan tes kemahiran bagi pemelajar asing bertujuan akademik. Selain itu, penelitian ini juga menggunakan desain penelitian R\&D (Research and Development) model Thiagarajan, Semmel \& Semmel (1974). Akan tetapi, penelitian ini hanya sampai pada tahap define karena penelitian ini merupakan studi awal atau studi pendahuluan dari model pengembangan.

Penelitian ini dilakukan di Yogyakarta. Pengumpulan data dilakukan dengan menggunakan teknik observasi, dokumentasi, angket, dan wawancara. Subjek penelitiannya adalah pemelajar asing, dosen pengajar yang di kelas- nya terdapat mahasiswa asing, dan pengelola program BIPA bertujuan akademik. Penelitian ini dilakukan dari Februari sampai dengan Juli 2018. Analisis data dalam penelitian ini dipilah menjadi tiga, yaitu analisis data dari hasil uji coba, analisis data dari pakar/praktisi, dan analisis dari uji coba tes pada pemelajar asing. Keabsahan data yang digunakan adalah trianggulasi data. Trianggulasi yang digunakan adalah trianggulasi sumber dan metode.

\section{HASIL DAN PEMBAHASAN}

Pengembangan tes kemahiran ini berangkat dari analisis kebutuhan lapangan yang menunjukkan hasil bahwa ada kebutuhan untuk adanya tes kemahiran seperti ini. Analisis kebutuhan digali dari pemelajar BIPA bertujuan akademik dan para pengajar. Pemelajar BIPA bertujuan akademik merupakan pemelajar BIPA, seorang penutur asing yang belajar bahasa Indonesia, dengan tujuan akademik, seperti studi lanjut, bekerja di lingkungan akademik, dan lainnya yang bidang kajiannya adalah urusan akademik. Selain itu, kebutuhan pengajar terkait ini juga dipaparkan dalam keasempatan kali ini. Bagian terakhirnya adalah berkaitan dengan kriteria tes kemahiran BIPA bertujuan akademik yang dibuat.

\section{Analisis Kebutuhan Pemelajar}

Ada 33 subjek penelitian ini, yakni para pemelajar asing yang bertujuan akademik dari berbagai universitas, seperti UNY, UAJY, UGM, UM, Unair, dan lainnya. Mereka adalah pemelajar BIPA yang sedang menempuh kelas bahasa Indonesia bertujuan akademik dan akan menjadi mahasiswa di Indonesia.

Data yang ada berdasar angket, ditemukan bahwa $84,84 \%$ dari universitas tempat para responden belajar menuntut persyaratan penguasaan bahasa Indonesia bagi mahasiswa asing yang akan belajar di dalamnya. Selain itu, mahasiswa asing juga merasa bahwa mereka membutuhkan suatu alat ukur untuk mengetahui tingkat penguasaannya terhadap bahasa Indonesia yang sedang dipelajarinya. Penguasaan akan bahasa Indonesia akademik dan budaya akademik merupakan hal penting bagi mereka. Hal ini ditemukan dalam penggalian data awal sebagai analisis kebutuhan pe- 
melajar. Visual data yang ada dalam penelitian ini disajikan pada Gambar 1.

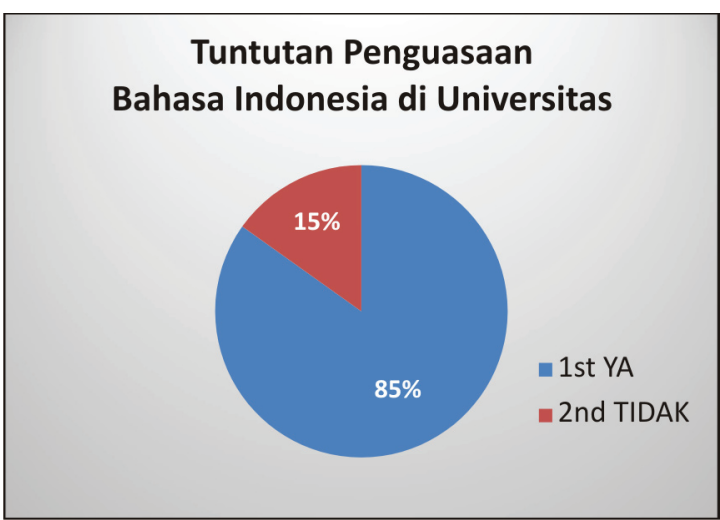

Gambar 1. Tuntutan Kemampuan Berbahasa

Indonesia bagi Pemelajar Asing

Dari 33 mahasiswa asing, 28 di antaranya menyatakan bahwa mereka belajar bahasa Indonesia karena universitas tempatnya akan berkuliah meminta meminta syarat penguasaan bahasa Indonesia. Mereka akan kuliah di kelas reguler dan bercampur dengan mahasiswa Indonesia. Oleh karena itu, mereka harus berbahasa Indonesia. Hal ini sesuai dengan PP RI Nomor 57 Tahun 2014 Pasal 20, ayat (1) yang menyatakan bahwa orang asing yang akan mengikuti pendidikan di Indonesia harus mampu berbahasa Indonesia. Beberapa tugas akhir mahasiswa juga diharapkan berbahasa Indonesia sehingga mereka harus menguasai bahasa Indonesia yang akademik untuk memperlancar studinya.

Sementara itu, mahasiswa juga mempunyai kesadaran bahwa ia memerlukan bahasa Indonesia sebagai sarana belajar di Indonesia. Bahasa Indonesia yang dipelajari tidak hanya yang komunikatif untuk kehidupan sehari-harinya, namun termasuk bahasa Indonesia akademik yang mereka butuhkan selama berkuliah nantinya. Data yang menunjukkan kebutuhan pemelajar akan bahasa Indonesia nampak dalam tampilan visual data pada Gambar 2 .
Kebutuhan Bahasa Indonesia Akademik bagi Mahasiswa Asing

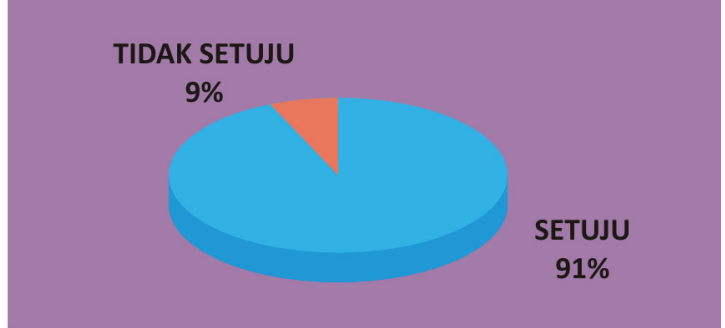

Gambar 2. Kebutuhan Bahasa Indonesia bagi Pemelajar Asing Akademik

Berdasarkan data dari angket, diketahui bahwa 30 orang dari 33 responden (91\%) yang ada menjawab bahwa mereka perlu menguasai bahasa Indonesia akademik. Mereka menyadari bahwa mereka akan lebih baik kuliahnya jika menguasai bahasa Indonesia dengan baik. Bahasa Indonesia akademik akan membantu mereka dalam memperlancar studi di Indonesia. Sebagian besar dari mereka adalah mahasiswa yang menggunakan beasiswa untuk kuliah di Indonesia sehingga mereka menginginkan agar dapat segera menyelesaikan perkuliahan di Indonesia sesuai tuntutan waktu dari beasiswa yang mereka terima. Selain, bahasa Indonesia mereka juga merasakan bahwa budaya akademik juga perlu mereka kuasai. Hasil data yang dijumpai dalam penelitian ini disajikan pada Gambar 3.

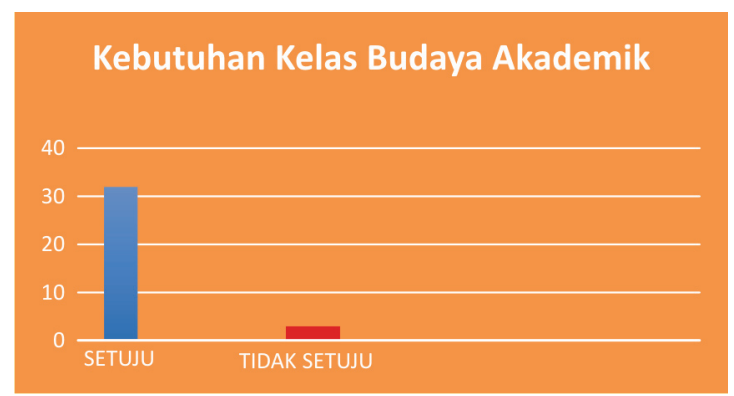

Gambar 3. Kebutuhan Pemelajar Asing akan Budaya Akademik Indonesia

Budaya akademik menjadi bagian erat yang tidak lepas ketika seseorang belajar di lingkungan tersebut. Budaya akademik berkaitan dengan tata cara kehidupan akademik kampus yang masing-masing tempat memiliki ciri yang khas. Para pemelajar asing 
ini merasakan bahwa kampus tempat mereka belajar sekarang tidak sama dengan kampus asal mereka sebelumnya di negara mereka masing-masing. Perbedaan budaya yang mereka rasakan ini membuat $100 \%$ dari responden menyatakan kesetujuan mereka dalam belajar budaya akademik. Menurut mereka, penguasaan budaya akademik dapat membantu mereka untuk dapat beradaptasi dengan lebih mudah di lingkungan kampus tempatnya belajar sekarang.

\section{Analisis Kebutuhan Pengajar}

Selain pemelajar, penelitian ini juga membidik pengajar sebagai subjek penelitian. Pengajar yang dimaksudkan dalam penelitian ini adalah para dosen pengampu mata kuliah yang di dalamnya terdapat mahasiswa asing yang ikut kuliah bersama mahasiswa Indonesia. Ada 7 dosen yang menjadi informan dan peneliti juga melakukan observasi di beberapa kelas yang diampunya.

Berdasar hasil observasi di kelas dan wawancara dengan para pengajar tersebut dijumpai fakta bahwa kemampuan bahasa Indonesia akademik mahasiswa asing akan sangat membantu proses pembelajarannya di kelas. Mahasiswa yang kurang mampu berbahasa Indonesia akademik akan cenderung diam dan pasif di kelas. Sekalipun dosen memberikan beberapa pancingan, mereka menjadi tidak responsif dan terkesan menghindar. Sementara bagi mahasiswa asing yang menguasai bahasa Indonesia dengan baik, mereka lebih nampak aktif dan mengikuti proses kelas dengan baik.

Para dosen menyatakan bahwa mereka juga kesulitan jika pemelajar asing di kelasnya kurang menguasai bahasa Indonesia. Dalam berbahasa Indonesia akademik di kelas, tentunya budaya akademik akan mengiringi tuturan tersebut. Penguasaan bahasa dan budaya akademik menjadi bagian penting dalam proses belajar mahasiswa asing di Indonesia. Para pengajar menyatakan bahwa para pemelajar asing perlu diuji kemahirannya sebelum masuk kelas reguler agar dosen dapat mengetahui kemampuan berbahasa Indonesia mahasiswa asing tersebut.

\section{Kriteria Tes Kemahiran BIPA Bertujuan Akademik}

Analisis kebutuhan lapangan menghasilkan kriteria tes kemahiran yang diharapkan. Kriteria tes kemahiran yang diharapkan akan dijadikan sebagai saran pengembangan produk awal tes kemahiran ini. Hal ini menjadikan tes kemahiran yang dibuat sesuai kebutuhan penggunanya. Untuk memperkuat kriteria tes kemahiran berbahasa Indonesia yang dirancang, peneliti mengamati pula tes-tes kemahiran yang ada saat ini.

Tes kemahiran berbahasa Indonesia sudah ada di Indonesia yang standart berlaku, yakni tes UKBI. Tes ini sebenarnya diperuntukkan buat penutur jati maupun penutur asing bahasa Indonesia. Tes penguasaan berbahasa asing yang banyak dikenal adalah TOEFL dan IELTS dalam bahasa Inggris. Penelitian ini menggabungkan UKBI dan IELTS menjadi bentukan tes yang digagas untuk pemelajar asing ini. Beberapa simpulan dari kajian tersebut antara lain sebagai berikut. Pertama, tes kemahiran berbahasa Indonesia tujuan akademik dapat mengacu pada tes kemahiran yang sudah ada sebelumnya, baik UKBI maupun TOEFL dan IELTS. Kedua, tes kemahiran berbahasa Indonesia tujuan akademik harus mencakup berbagai aspek kompetensi berbahasa, baik keterampilan berbahasa maupun pengetahuan bahasa. Ketiga, tes kemahiran ini hendaknya

Tabel 1. Kriteria Tes Kemahiran BIPATA

\begin{tabular}{ll}
\hline \multicolumn{1}{c}{ Aspek Kriteria Tes } & \multicolumn{1}{c}{ Uraian Kriteria } \\
\hline Acuan & Tipe tes mengacu pada UKBI, TOEFL, dan IELTS \\
Cakupan & $\begin{array}{l}\text { Keterampilan berbahasa Indonesia (menyimak, berbicara, membaca, } \\
\text { menulis), pengetahuan bahasa (tata bahasa dan kosakata), dan budaya } \\
\text { akademik Indonesia }\end{array}$ \\
Potensi khusus & Kontekstual dan aktual \\
Jenjang soal & C1 sampai dengan C6 \\
\hline
\end{tabular}


kontekastual dan memberi gambaran faktual yang berkaitan dengan dunia kampus atau akademik. Keempat, cakupan kompetensi yang diuji dalam tes kemahiran ini harus meliputi semua tataran, dari ingatan sampai bentuk aplikasi pemakaian bahasanya (C1 sampai dengan C6).

\section{SIMPULAN}

Dari pembahasan di atas, dapat disimpulkan bahwa pemelajar asing memerlukan sebuah alat ukur kemampuan berbahasa Indonesia akademiknya, yakni dengan tes kemahiran berbahasa akademik. Selain itu, jenis tes yang ada saat ini, yakni UKBI, perlu dikembangkan agar sesuai dengan pemelajar asing. Dengan diterapkannya piranti tes kemahiran berbahasa Indonesia yang berbeda dengan penutur asli, maka institusi BIPA akan lebih mudah memetakan kemampuan berbahasa Indonesia pemelajar asing.

\section{DAFTAR PUSTAKA}

Robinson, P. (Ed.) (2002). Individual Differences and Instructed Language Learning. Volume 2. Philadelphia: John Benjamin Publishing Company.

Rogers, A. (1999). Teaching Adults (2nd edition). Philadelpia: Open University Press.

Lighbown, P. M. \& Spada, N. (2013). How Language are Learned (Fourth Edition). Oxford: Oxford University Press.

Ellis, R. (1995). The Study of Second Language Acquisition. Oxford: Oxford University Press.

Fry, H., Ketteridge, S., dan Marshall, S. (Eds.). (2013). Handbook Teaching and Learning (Strategi Peningkatan Mutu Pendidikan di Perguruan Tinggi).
Terjemahan dari Handbook Teaching and Learning in Higher Education (Enhancing Academic Practice) oleh Ahmad Asnawi. Riau: Zanafa Publishing.

Harris, D.P. (1969). Testing English as A Second Language. New York: Mc-GrawHill company. Hayland, K. 2006. English for Academic Purposes - an advanced resource book. E-book. London: Routledge.

Illeris, K. 2011. Contemporary Theories of Learning. Diterjemahkan oleh M. Khozim dalam Teori-teori Pembelajaran Kontemporer. Bandung: Nusa Media.

Kusmiatun, A. (2015). Mengenal BIPA (Bahasa Indonesia bagi Penutur Asing) dan Pembelajarannya. Yogyakarta: KMedia.

Kusmiatun, A. (2017). BIPA Bertujuan Akademik. Disertasi tidak diterbitkan. Universitas Negeri Malang.

Leaver, B. L., Ehrman, M., and Shekhtman, B. 2005. Achieving Success in Second Language Acquisition. Cambridge: Cambridge University Press.

Djiwandono, M.S. (2008). Tes Bahasa: Pegangan bagi Pengajar Bahasa. Jakarta: PT. Indeks.

Suyitno, I. (2005). Bahasa Indonesia untuk Penutur Asing (Teori, Strategi, dan Aplikasi Pembelajarannya). Yogyakarta: CV. Grafika Indah.

Thiagarajan, S., Dorothy S. S., dan Melvyn I. S. (1974). Intructional Development for Training Teachers of Exceptional Children. Washington DC: National Center for Improvement Educational System. 